\title{
Can the blood urea nitrogen to serum albumin ratio be used as a mortality predictor in patients with pneumonia after cardiac surgery?
}

\author{
Ahmet Kağan As ${ }^{1} \oplus$, Arda Aybars Pala ${ }^{1}$, Orhan Güvenç²®, Şenol Yavuz ${ }^{1} \oplus$ \\ ${ }^{1}$ Department of Cardiovascular Surgery, University of Health Sciences, Bursa Yüksek Ihtisas Training and Research Hospital, Bursa, \\ Turkey \\ ${ }^{2}$ Department of Cardiovascular Surgery, Uludă̆ University Medical Faculty, Bursa, Turkey
}

\section{ABSTRACT}

Objectives: Serious complications are seen after cardiac surgery operations. Postoperative pneumonia is one of the most important of these complications. Some biomarkers have been examined in the prediction of mortality in special groups such as hospital-acquired pneumonia or aspiration pneumonia. In addition to parameters such as blood-urea nitrogen and albumin, the blood urea nitrogen to albumin ratio obtained by the ratio of these two parameters is also used as a mortality predictor. In this study, it was aimed to investigate the effect of the blood urea nitrogen to albumin ratio at the time of diagnosis of pneumonia on mortality in patients who developed pneumonia in the early period after cardiac surgery.

Methods: In this study, 138 patients who developed pneumonia in the early period after cardiac surgery were examined. Complete blood count and biochemical test results were analyzed for all patients, and differences between groups were investigated. The patients who developed in-hospital pneumonia and were discharged as survivors were classified as Group 1, and non-survivor patients were determined as Group 2.

Results: Patients who did not develop in-hospital mortality were included in Group $1(\mathrm{n}=105$, mean age $=$ $63.7 \pm 9.2$ years), and those with non-survivor were included in Group $2(n=33$, mean age $=66.9 \pm 9.6$ years $)$. At the time of diagnosis neutrophil-lymphocyte ratio, C-reactive protein, blood-urea nitrogen and blood urea nitrogen to albumin ratio values were significantly higher in Group $2(p<0.001, p<0.001, p=0.004$ and $p<$ 0.001 ; respectively) ROC curve analysis was performed to evaluate blood urea nitrogen to albumin ratio in predicting mortality. The cut-off value of blood urea nitrogen to albumin ratio was 4.1 (Area under the curve [AUC]: $0.740,95 \%$ CI: $0.690-0.820, p<0.001$, with sensitivity of $72.5 \%$ and specificity of $68.6 \%$ ).

Conclusions: In pneumonia developing after cardiac surgery, we found that the peripheral blood blood urea nitrogen to albumin ratio at the time of the first symptom in the patient has a high predictive power for the development of mortality in this particular patient group.

Keywords: Cardiac surgery, postoperative pneumonia, mortality, prediction

$\mathrm{C}$ ardiac surgery is a procedure that is applied with high success rates in the treatment of cardiovascular diseases, and various serious complications after these operations still maintain their importance [1]. Postoperative pneumonia is one of the most important complications [2]. Due to this complication, the length 
of hospital stay is prolonged, and the risk of morbidity and mortality increases. Previous studies reported that the rate of development of postoperative pneumonia has been shown to be between $5 \%$ and $21 \%$, and mortality rates in these cases range from $6.2 \%$ to $28 \%$ [25].

Various inflammatory markers obtained from routine blood parameters have been the subject of research in cardiovascular surgery. These markers have been used both in the diagnostic sense and in predicting the prognosis of developing complications $[6,7]$. Albumin, as a negative acute phase reactant, is an important inflammatory marker and plays an important role in maintaining osmotic pressure and in interstitial transport of vital molecules [8]. Increased blood urea nitrogen (BUN) levels in blood is also an important indicator of dehydration and has poor prognostic importance in pneumonia patients [9]. In the light of this information, blood urea nitrogen to albumin $(\mathrm{B} / \mathrm{A})$ ratio seems to be an important marker. In two recent studies, B/A ratio has been shown as an independent predictor of mortality in patients with hospital-acquired pneumonia and aspiration pneumonia $[10,11]$.

In this current study, we aimed to investigate the effect of the $\mathrm{B} / \mathrm{A}$ ratio at the time of diagnosis of pneumonia on mortality in cases who developed early pneumonia after cardiac surgery.

\section{METHODS}

This study was approved with the protocol dated 09.06.2021 and numbered 2011-KAEK-25 2021/0616 of the Bursa Yüksek İhtisas Training and Research Hospital Clinical Research Ethics Committee. In this study, which was planned as a single center, patients between the ages of 20-90 who underwent open heart surgery at Bursa Yüksek İhtisas Training and Research Hospital between January 01, 2014 and January 01, 2020 were included in the study. The patients who had undergone redo cardiac operation, emergency cases, those with a known history of lung disease, those with chronic renal failure, and those with a history of pneumonia were excluded from the study. A total of 138 patients were evaluated for the study.

Laboratory values, demographic characteristics and blood values on the day they were diagnosed with pneumonia were recorded for all patients at the time of admission to the hospital. The patients who developed in-hospital pneumonia and were discharged as survivor were classified as Group 1, and non-survivor patients were classified as Group 2.

\section{Variables}

Variables were recorded as of the first admission of the patients to the hospital. Demographic data, identity information, age, gender, smoking were determined and recorded. Their medical histories were analyzed in detail. Presence of hypertension, diabetes, chronic obstructive pulmonary disease, congestive heart failure and coronary artery disease were recorded. By following the clinical outcome; Discharge or death information, duration of intensive care stay and total hospital stay were noted. Laboratory data including complete blood count values (white blood cell [WBC], hemoglobin [Hb], neutrophil, lymphocyte, platelet [PLT]), neutrophil-lymphocyte ratio (NLR), C-reactive protein (CRP), biochemical studies (BUN, Albumin, B/A ratio) was recorded. In addition, inflammatory blood markers were recorded on the basis of the day of diagnosis of pneumonia, and the $\mathrm{B} / \mathrm{A}$ ratio was recalculated.

\section{Postoperative Pneumonia Diagnosis}

In patients with clinically suspected pneumonia, newly detected infiltration on chest X-ray or an increase in the current infiltration degree were taken into account. In addition, pneumonia was diagnosed with the presence of at least two of the following criteria [12]: 1) Fever $\left(>38.5^{\circ} \mathrm{C}\right)$ or hypothermia $\left(<36.0^{\circ} \mathrm{C}\right)$; 2) Presence of purulent tracheo-bronchial secretion or an increase in the amount of existing secretion; and 3) Leukocytosis $(12,000 / \mu \mathrm{L})$ or leukopenia $(4,000 / \mu \mathrm{L})$.

\section{Statistical Analysis}

Data were analyzed by SPSS 21.0 (IBM Statistical Package for the Social Sciences Statistic Inc. version 21.0, Chicago, IL, USA) program. "KolmogorovSmirnov test and Shapiro-Wilk test" were used for normality distribution analysis. While "Student's $t$ test was used for the data presenting normal distribution, Mann-Whitney U test was used for data that did not conform to normal distribution. These data were shown as mean \pm standart deviation or as median (minimum-maximum) respectively. Categorical variables were shown as frequency and percentage, and 
"Chi Square test" was used for analysis. Multivariate binary logistic regression analysis was utilized to analyze mortality predictors. A $p$ value's being less than 0.05 was accepted statistically significant. In predicting in-hospital mortality, receiver operating characteristics (ROC) curve analysis was performed for $\mathrm{B} / \mathrm{A}$ ratio and area under the curve (AUC) was calculated.

\section{RESULTS}

A total of 138 patients were included in the study. Patients who did not develop in-hospital mortality were included in Group $1(\mathrm{n}=105$, mean age $=63.7$ \pm 9.2 years), and those with non-survivor were included in Group $2(\mathrm{n}=33$, mean age $=66.9 \pm 9.6$ years). There were no statistically significant differ- ences between the two groups in terms of age, gender, body mass index, smoking, hypertension and chronic obstructive pulmonary disease rates $(p>0.05)$. Also preoperative blood parameters of the patients were similar between two groups. Demographic characteristics and preoperative blood parameters of all patients are presented in Table 1.

Operative and postoperative features and blood parameters of the patients at the time of diagnosis were shown in Table 2. The two groups were similar in terms of perfusion times, need of positive inotropic support and use of blood products. There were no statistically significant differences between the two groups in terms of (at the time of diagnosis) WBC, creatinine, neutrophil counts, lymphocyte counts and albumin values $(p>0.05)$. At the time of diagnosis NLR, CRP, BUN and B/A ratio values were signifi-

Table 1. Preoperative features and preoperative laboratory variables of the patients

\begin{tabular}{|c|c|c|c|}
\hline Variables & $\begin{array}{c}\text { Group } 1 \\
\text { (Survivor) } \\
(\mathbf{n}=\mathbf{1 0 5})\end{array}$ & $\begin{array}{c}\text { Group } 2 \\
\text { (Non-Survivor) } \\
(\mathbf{n}=\mathbf{3 3})\end{array}$ & $p$ value \\
\hline Age (years) & $63.7 \pm 9.2$ & $66.9 \pm 9.6$ & 0.179 \\
\hline Male gender, n (\%) & $73(69.5 \%)$ & $25(75.8 \%)$ & 0.491 \\
\hline BMI (kg/m2) & $26.4(22.4-38)$ & $27.2(21.6-39)$ & 0.293 \\
\hline Hypertension, n (\%) & $61(58.1 \%)$ & $21(63.6 \%)$ & 0.572 \\
\hline Diabetesmellitus, n (\%) & $30(28.6 \%)$ & $14(42.4 \%)$ & 0.136 \\
\hline COPD, n (\%) & $25(23.8 \%)$ & $11(33.3 \%)$ & 0.277 \\
\hline Smoking, n (\%) & $23(21.9 \%)$ & $8(24.2 \%)$ & 0.779 \\
\hline Hiperlipidemia, n (\%) & $54(51.4 \%)$ & $15(45.5 \%)$ & 0.549 \\
\hline Ejection fraction (\%) & $54.2 \pm 9.7$ & $50.2 \pm 9.6$ & 0.209 \\
\hline White blood cell $(103 / \mu \mathrm{L})$ & $9.2(4.9-12.4)$ & $8.9(5.1-13.7)$ & 0.259 \\
\hline Hemoglobin (mg/dl) & $12.8(10-15.7)$ & $12.2(10.4-16)$ & 0.314 \\
\hline Platelet $(103 / \mu \mathrm{L})$ & $254.2(129-460.4)$ & $258.5(128-450)$ & 0.204 \\
\hline Neutrophil $(103 / \mu \mathrm{L})$ & $4.2(1.8-5.7)$ & $4.4(2.5-6.9)$ & 0.251 \\
\hline Lymphocyte $(103 / \mu \mathrm{L})$ & $2(0.8-4.1)$ & $1.8(0.9-4.5)$ & 0.102 \\
\hline NLR & $2.3(1.4-13.4)$ & $2.4(1.3-11.9)$ & 0.096 \\
\hline Creatinine (mg/dL) & $1.1 \pm 0.8$ & $1.3 \pm 0.7$ & 0.495 \\
\hline BUN, (mg/dL) & $12(9-18)$ & $13(10-20)$ & 0.229 \\
\hline Albumin, (g/dL) & $4.2(3.95 .5)$ & $4.3(3.8-5.4)$ & 0.375 \\
\hline CRP (mg/L) & $6.9(0.5-12)$ & $6.2(0.6-15)$ & 0.194 \\
\hline $\mathrm{B} / \mathrm{A}$ ratio $(\mathrm{mg} / \mathrm{g})$ & $1.96(0.4-4.1)$ & $2.08(0.5-4.9)$ & 0.174 \\
\hline
\end{tabular}

$\mathrm{BMI}=$ Body mass index, $\mathrm{COPD}=$ Chronic obstructive pulmonary disease, $\mathrm{BUN}=\mathrm{Blood}$ urea nitrogen, $\mathrm{NLR}=$ Neutrophil to lymphocyte ratio, $\mathrm{CRP}=\mathrm{C}$-reactive protein, $\mathrm{B} / \mathrm{A}$ ratio $=\mathrm{Blood}$ urea nitrogen to albumin ratio 
cantly higher in Group $2(p<0.001, p<0.001, p=$ 0.004 and $p<0.001$; respectively).

Logistic regression analysis was performed to evaluate the predictive value of certain parameters in terms of in-hospital mortality (Table 3). In univariate analysis, age $>70$ years (OR [odds ratio]: $1.125,95 \%$ CI [confidence interval]: $1.080-1.548, \mathrm{p}=0.014)$, ejection fraction $<35 \%$ (OR: $1.956,95 \% \mathrm{CI}: 1.318$ $2.865, P=0.002$ ), need for inotropic support (OR: $0.875,95 \%$ CI: $0.582-0.961, p=0.036)$, Time of di-

Table 2. Operative and postoperative features of thepatients

\begin{tabular}{lccc}
\hline Variables & $\begin{array}{c}\text { Group 1 } \\
(\mathbf{n = 1 0 5})\end{array}$ & $\begin{array}{c}\text { Group 2 } \\
(\mathbf{n = 3 3})\end{array}$ & P value \\
\hline Total perfusion time $(\mathrm{min})$ & $86(65-210)$ & $88(68-196)$ & 0.148 \\
\hline Cross-clamp time $(\mathrm{min})$ & $55(22-145)$ & $52(25-150)$ & 0.362 \\
\hline Combined surgery, $\mathrm{n}(\%)$ & $23(21.9 \%)$ & $8(24.2 \%)$ & 0.779 \\
\hline Packed blood products (units) & $6(4-12)$ & $7(4-14)$ & 0.194 \\
\hline Inotropic support, $\mathrm{n}(\%)$ & $30(28.6 \%)$ & $16(48.5 \%)$ & $\mathbf{0 . 0 3 4}$ \\
At the time of diagnosis & & & \\
White blood cell $(103 / \mu \mathrm{L})$ & $12.9(13.2-21.8)$ & $13.1(11.3-25.6)$ & 0.107 \\
Neutrophil $(103 / \mu \mathrm{L})$ & $4.2(2.8-8.4)$ & $4.4(2.6-9.7)$ & 0.075 \\
\hline Lymphocyte $(103 / \mu \mathrm{L})$ & $1.5(0.9-2.1)$ & $1.2(1-2.5)$ & 0.152 \\
\hline NLR & $3.2(2.1-15.4)$ & $4.9(2.4-22.6)$ & $<\mathbf{0 . 0 0 1}$ \\
Creatinine $(\mathrm{mg} / \mathrm{dL})$ & $1.2(0.9-1.6)$ & $1.1(0.7-2)$ & 0.192 \\
BUN $(\mathrm{mg} / \mathrm{dL})$ & $12(8.5-28.6)$ & $15.6(8-46.8)$ & $\mathbf{0 . 0 0 4}$ \\
Albumin $(\mathrm{g} / \mathrm{dL})$ & $3.6(2.6-4.4)$ & $3.5(2.4-4.2)$ & 0.076 \\
\hline B/A ratio $(\mathrm{mg} / \mathrm{g})$ & $3.36(0.38-10.08)$ & $4.89(1.18-18.9)$ & $<\mathbf{0 . 0 0 1}$ \\
\hline CRP $(\mathrm{mg} / \mathrm{L})$ & $154(85-350)$ & $238(120-450)$ & $<\mathbf{0 . 0 0 1}$ \\
\hline
\end{tabular}

$\mathrm{NLR}=$ Neutrophil to lymphocyte ratio, $\mathrm{BUN}=\mathrm{Blood}$ urea nitrogen, $\mathrm{B} / \mathrm{A}$ ratio $=$ Blood urea nitrogen to albumin ratio, $\mathrm{CRP}=\mathrm{C}$-reactive protein

Table 3. Logistic regression analysis to identify factors affecting postoperative pneumonia mortality

\begin{tabular}{lcccccc}
\hline Variables & \multicolumn{3}{c}{ Univariate analysis } & \multicolumn{3}{c}{ Multivariate analysis } \\
& $\boldsymbol{p}$ value & $\begin{array}{c}\text { Exp (B) Odds } \\
\text { Ratio }\end{array}$ & $\begin{array}{c}\mathbf{9 5 \%} \text { C.I. } \\
\text { Lower Upper }\end{array}$ & $\boldsymbol{p}$ value & $\begin{array}{c}\text { Exp (B) Odds } \\
\text { Ratio }\end{array}$ & $\begin{array}{c}\text { 95\% C.I. } \\
\text { Lower Upper }\end{array}$ \\
\hline Age $>70$ years & $\mathbf{0 . 0 1 4}$ & 1.125 & $1.080-1.548$ & 0.276 & 1.345 & $0.844-1.694$ \\
\hline $\begin{array}{l}\text { Ejection fraction }< \\
\text { 35\% }\end{array}$ & $\mathbf{0 . 0 0 2}$ & 1.956 & $1.318-2.865$ & 0.019 & 1.127 & $1.045-1.539$ \\
COPD & & & & & & - \\
Inotropic support & $\mathbf{0 . 0 3 6}$ & 0.875 & $0.582-0.961$ & 0.332 & 0.976 & $0.882-1.145$ \\
Preop NLR & 0.098 & 0.763 & $0.594-1.110$ & -- & -- & -- \\
\hline Preop B/A ratio & 0.175 & 0.976 & $0.775-1.194$ & -- & -- & -- \\
Td NLR & $<\mathbf{0 . 0 0 1}$ & 1.554 & $1.196-2.872$ & 0.094 & 0.887 & $0.697-1.148$ \\
\hline Td B/A ratio & $<\mathbf{0 . 0 0 1}$ & 1.668 & $1.441-2.152$ & $<\mathbf{0 . 0 0 1}$ & 1.224 & $1.090-1.792$ \\
\hline Td CRP & $<\mathbf{0 . 0 0 1}$ & 3.336 & $2.178-4.894$ & $<\mathbf{0 . 0 0 1}$ & 2.628 & $1.945-4.136$ \\
\hline
\end{tabular}

$\mathrm{COPD}=$ Chronic obstructive pulmonary disease, $\mathrm{NLR}=$ Neutrophil to lymphocyte ratio, $\mathrm{B} / \mathrm{A}$ ratio = Blood urea nitrogen to albumin ratio, $\mathrm{CRP}=\mathrm{C}$-reactive protein, $\mathrm{Td}=$ Time of diagnosis 
agnosis (Td) NLR (OR: 1.554, 95\% CI: 1.196-2.872, $p<0.001$ ), Td B/A ratio (OR: $1.668,95 \%$ CI: $1.441-$ 2.152, $p<0.001)$ and Td CRP (OR: 3.336, 95\% CI: $2.178-4.894, p<0.001)$ values were found to be significantly correlated with the development of in-hospital mortality. As a result of multivariate analysis, ejection fraction< 35\% (OR: 1.127 CI 95\%: 1.045 $1.539, p=0.019$ ), $\mathrm{Td} \mathrm{B} / \mathrm{A}$ ratio (OR: $1.224, \mathrm{CI}$ 95\%:1.090-1.79452, $p<0.001$ ) and Td CRP (OR: 2.628, CI 95\%: 1.945-4.136, $p<0.001)$ values were determined as independent predictors for predicting in-hospital mortality.

ROC curve analysis was performed to evaluate $\mathrm{B} / \mathrm{A}$ ratio in predicting mortality. The cut-off value of $\mathrm{B} / \mathrm{A}$ ratio was 4.1 (Area under the curve [AUC]: 0.740, 95\% CI: $0.690-0.820, p<0.001$, with sensitivity of $72.5 \%$ and specificity of $68.6 \%$ ) (Fig. 1).

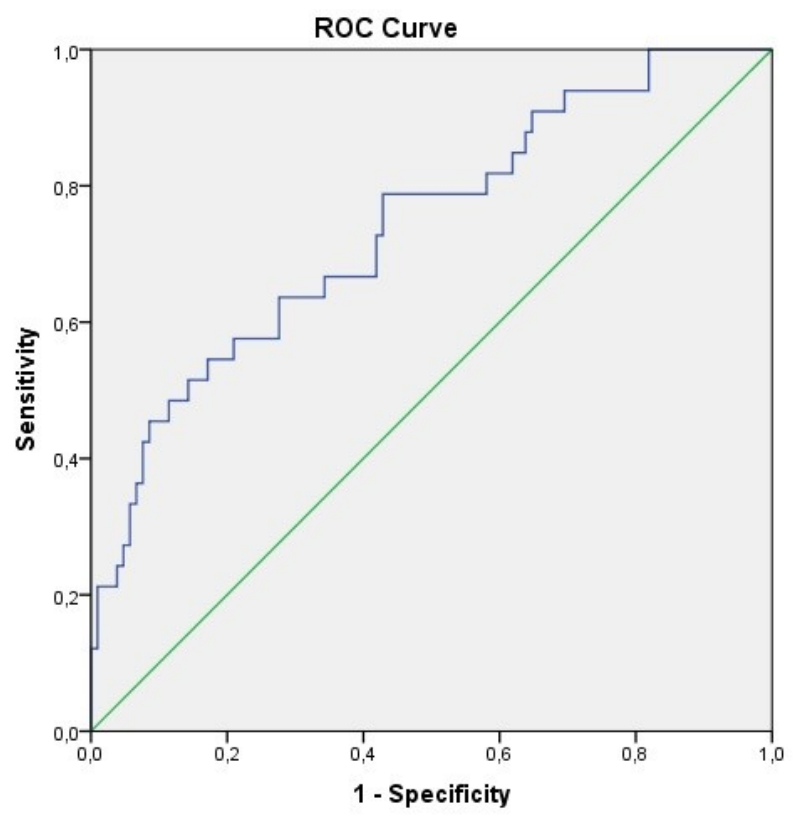

Fig. 1. The area under the curve (AUC), confidence interval (CI), and cut-off values in receiver-operating characteristic (ROC) curve analysis for $\mathrm{B} / \mathrm{A}$ ratio to predict mortality (cut off:4.1, AUC: $0.740,95 \%$ CI: $0.690-0.820, p<0.001$, with $72.5 \%$ sensitivity and $68.6 \%$ specificity).

\section{DISCUSSION}

Postoperative pneumonia is one of the most important complications after open heart surgery. In addition to prolonging hospitalizations, this may result in mortality rates up to $50 \%$. In this current study, it was shown for the first time in the literature that the $\mathrm{B} / \mathrm{A}$ ratio is an independent predictor of mortality in cases of pneumonia occurring in the early period after cardiac surgery. In addition to this marker, CRP value and ejection fraction below $35 \%$ at the time of diagnosis of pneumonia were also determined as independent predictors of mortality.

Serum albumin plays a key role in maintaining physiological homeostasis. It undertakes important tasks such as balancing osmotic pressure and transporting some components in the blood. The presence of low albumin levels in some chronic diseases such as heart failure, COPD and diabetes, as well as in malignancies with a predominant course of catabolism, has been associated with increased mortality and morbidity [13]. In a study by Yayla et al. [14], albumin levels were found to be significantly lower in patients who developed saphenous vein occlusion after CABG operations. In other studies, significant correlations were found between atrial fibrillation developing after cardiac surgery and low albumin $[15,16]$. In our study, we found that albumin levels at the time of pneumonia diagnosis were low in patients who developed mortality, although it was not statistically significant $(p=$ 0.076).

Dehydration may occur in patients who need hospitalization, especially in infectious diseases where inflammation is at the forefront. The resulting increase in urea reabsorption from the kidneys results in increased BUN levels. This value is an important parameter indicating the state of dehydration in individuals and has been associated with poor clinical outcomes in patients with heart failure and pneumonia $[9,17]$. In a study by Akgül et al. [16], a significant relationship was found between the development of postoperative atrial fibrillation, which is closely related to inflammation, and high BUN values after CABG operations. In our patients, BUN values at the time of diagnosis of pneumonia were significantly higher in the mortality group ( $p=0.004)$.

In line with all this literature information, the $\mathrm{B} / \mathrm{A}$ ratio emerges as a valuable prognostic marker. There are various studies on various medical problems and $\mathrm{B} / \mathrm{A}$ ratio in the literature. In a study conducted by Bae et al. [18] on patients with ischemic stroke, the B/A ratio was shown as a poor prognostic marker. In a study conducted by Dundar et al. [19], the B/A ratio at the time of admission was shown as an independent predictor of mortality in patients over the age of 65 who applied to the emergency department. In addition, 
the authors emphasized in this study that the $\mathrm{B} / \mathrm{A}$ ratio is a stronger predictor than albumin, BUN, creatinine, and glomerular filtration ratio alone [19]. In another study by Fang and XU [20], B/A ratio was found to be a strong predictor of mortality in critically ill patients in intensive care units who developed pulmonary embolism.

Recently, the relationship between $\mathrm{B} / \mathrm{A}$ ratio and mortality in various pneumonia cases has been the subject of research. In the article published by Feng et al. [10] in 2019, the effect of B/A ratio on mortality in hospital-acquired pneumonia cases was investigated. In the study, which included 1158 cases, 150 patients $(13 \%)$ died within 30 days. At the end of their study, the authors determined the high $\mathrm{B} / \mathrm{A}$ ratio as an important value in predicting 30-day mortality [10]. In a study by Ryu et al. [11], at the beginning of 2021, the relationship between $\mathrm{B} / \mathrm{A}$ ratio and mortality in aspiration pneumonia cases was investigated. In the study, which included 443 patients, mortality was observed in $90(20.3 \%)$ patients in the first 28 days. As a result of the multivariate analysis, a B/A ratio above 7 was shown as a strong and independent predictor of mortality (OR 3.40, 95\% CI 1.87-6.21, $p<0.001$ ). In another recent study by Ata et al. [21], B/A ratio was found to be an independent predictor for mortality in intensive care patients with COVID-19 pneumonia.

In our study, the other independent predictors of mortality in patients who developed pneumonia, apart from the $\mathrm{B} / \mathrm{A}$ ratio, were preoperative ejection fraction below 35\% and high CRP at the time of diagnosis. Comprehensive studies and meta-analyses have similar results with our study. Having a low ejection fraction in pneumonia that develops after cardiac surgery plays an important role in both the development of postoperative pneumonia and mortality after pneumonia [2, 12, 22-24]. Similarly, there are studies showing that increased CRP levels are also important in the development of postoperative pneumonia and associated mortality [25-27].

\section{Limitations}

The most important limitations of our study are that it is single-centered, retrospective, and the number of patients is low. More comprehensive publications with larger numbers of patients are needed to support existing data.

\section{CONCLUSION}

In our study, we examined a patient group that developed pneumonia after open heart surgery, which has not been evaluated in the literature before. In pneumonia developing after cardiac surgery, we found that the peripheral blood $\mathrm{B} / \mathrm{A}$ ratio at the time of the first symptom in the patient has a high predictive power for the development of mortality in this particular patient group. This predictive ability will enable us to predict the risk of pneumonia-related mortality in patients undergoing cardiac surgery and to prevent adverse outcomes by taking necessary precautions in these patients.

\section{Authors' Contribution}

Study Conception: AKA, AAP; Study Design: AKA, AAP; Supervision: AKA, AAP, ŞY; Funding: AKA, AAP, OG; Materials: AKA, AAP, OG; Data Collection and/or Processing: AKA, AAP, OG; Statistical Analysis and/or Data Interpretation: AKA, AAP, OG, ŞY; Literature Review: AKA, AAP, OG, ŞY; Manuscript Preparation: AKA, AAP, OG, ŞY and Critical Review: AKA, AAP, OG, ŞY.

\section{Conflict of interest}

The authors disclosed no conflict of interest during the preparation or publication of this manuscript.

\section{Financing}

The authors disclosed that they did not receive any grant during conduction or writing of this study.

\section{REFERENCES}

1. Gucu A, Ozluk OA, Sunbul SA, Engin M, Seker IB, Sunbul A. Prognostic nutritional index as a marker of mortality: an observational cohort study of patients undergoing cardiac surgery. Rev Cardiovasc Med 2021;22:499-503.

2. Hortal J, Muñoz P, Cuerpo G, Litvan H, Rosseel PM, Bouza E; European Study Group on Nosocomial Infections; European Workgroup of Cardiothoracic Intensivists. Ventilator-associated pneumonia in patients undergoing major heart surgery: an incidence study in Europe. Crit Care 2009;13:R80.

3. Ibañez J, Riera M, Amezaga R, Herrero J, Colomar A, Campillo-Artero C, et al. Long-term mortality after pneumonia in cardiac surgery patients: a propensity-matched analysis. J Intensive Care Med 2016;31:34-40.

4. Kollef MH, Sharpless L, Vlasnik J, Pasque C, Murphy D, 
Fraser VJ. The impact of nosocomial infections on patient outcomes following cardiac surgery. Chest 1997;112:666-75.

5. Tamayo E, Álvarez FJ, Martínez-Rafael B, Bustamante J, Bermejo-Martin JF, Fierro I, et al. Valladolid Sepsis Study Group. Ventilator-associated pneumonia is an important risk factor for mortality after major cardiac surgery. J Crit Care 2012;27:18-25. 6. Engin M, Ozsin KK, Savran M, Guvenc O, Yavuz S, Ozyazicioglu AF. Visceral adiposity index and prognostic nutritional index in predicting atrial fibrillation after on-pump coronary artery bypass operations: a prospective study. Braz J Cardiovasc Surg 2021;36:522-9.

7. Perry LA, Liu Z, Loth J, Penny-Dimri JC, Plummer M, Segal $\mathrm{R}$, et al. Perioperative neutrophil-lymphocyte ratio predicts mortality after cardiac surgery: systematic review and meta-analysis. J Cardiothorac Vasc Anesth 2021. doi: 10.1053/j.jvca.2021.07.001.

8. Erdolu B, Engin M. Can C-reactive protein to albumin ratio be used as a predictor of amputation development in acute lower extremity ischemia? J Surg Med 2020;4:501-4.

9. Ito A, Ishida T, Tokumasu H, Washio Y, Yamazaki A, Ito Y, et al. Prognostic factors in hospitalized community-acquired pneumonia: a retrospective study of a prospective observational cohort. BMC Pulm Med 2021;17:78.

10. Feng DY, Zhou YQ, Zou XL, Zhou M, Yang HL, Chen XX, et al. Elevated blood urea nitrogen-to-serum albumin ratio as a factor that negatively affects the mortality of patients with hospital-acquired pneumonia. Can J Infect Dis Med Microbiol 2019;2019:1547405.

11. Ryu S, Oh SK, Cho SU, You Y, Park JS, Min JH, et al. Utility of the blood urea nitrogen to serum albumin ratio as a prognostic factor of mortality in aspiration pneumonia patients. Am J Emerg Med 2021;43:175-9.

12. Köse A, Yurtseven N, Yakın Düzyol İ. Ventilator associated pneumonia after open heart surgery: risk factors. J CardiovascThorac Anaesth Intensive Care Soc 2019;25:181-9.

13. Herrmann FR, Safran C, Levkoff SE, Minaker KL. Serum albumin level on admission as a predictor of death, length of stay, and readmission. Arch Intern Med 1992;152:125-30.

14. Yayla C, Gayretli Yayla K. C-reactive protein to albumin ratio in patients with saphenous vein graft disease. Angiology 2021;72:770-5.

15. Karabacak K, Kubat E, Akyol FB, Kadan M, Erol G, Doğanc1 $\mathrm{S}$, et al. The C-reactive protein/albumin ratio as a new predictor for postoperative atrial fibrillation after coronary artery bypass graft surgery. J Card Surg 2020;35:2747-53.

16. Akgul E, Parlar AI, Erkul GSA, Erkul S, Cekirdekci A. Investigation of the effect of preoperative hypoalbuminemia, blood urea nitrogen and creatinine levels on postoperative atrial fibrillation on off-pump coronary bypass surgery patients. Heart Surg Forum 2020;23:E641-6.

17. Aronson D, Mittleman MA, Burger AJ. Elevated blood urea nitrogen level as a predictor of mortality in patients admitted for decompensated heart failure. Am J Med 2004;116:466-73.

18. Bae SJ, Lee SH, Yun SJ, Kim K. Usefulness of the blood urea nitrogen-to-serum albumin ratio as a prognostic indicator of severity in acute ischemic stroke. Signa Vitae 2021;17:163-70.

19. Dundar ZD, Kucukceran K, Ayranci MK. Blood urea nitrogen to albumin ratio is a predictor of in-hospital mortality in older emergency department patients. Am J Emerg Med 2021;46:34954.

20. Fang J, Xu B. Blood urea nitrogen to serum albumin ratio independently predicts mortality in critically ill patients with acute pulmonary embolism. Clin Appl Thromb Hemost 2021;27:10760296211010241.

21. Ata F, As AK, Engin M, Kacmaz Kat N, Ata Y, Turk T. Can blood urea nitrogen-to-albumin ratio predict mortality in patients with moderate-to-severe COVID-19 pneumonia hospitalized in the intensive care unit? Rev Assoc Med Bras (1992) 2021;67:1421-6.

22. Bouza E, Pérez A, Muñoz P, Jesús Pérez M, Rincón C, Sánchez C, et al. Cardiovascular Infection Study Group. Ventilator-associated pneumonia after heart surgery: a prospective analysis and the value of surveillance. Crit Care Med 2003;31:1964-70.

23. Sheng W, Chi YF, Hou WM, Sun L, Niu ZZ, Sun Y et al. [Clinical analysis of 105 cases of ventilator-associated pneumonia after heart surgery]. Zhonghua Xin Xue Guan Bing Za Zhi 2012;40:825-9. [Article in Chinese].

24. Ailawadi G, Chang HL, O'Gara PT, O'Sullivan K, Woo YJ, DeRose JJ Jr, et al. Pneumonia after cardiac surgery: experience of the National Institutes of Health/Canadian Institutes of Health Research Cardiothoracic Surgical Trials Network. J Thorac Cardiovasc Surg 2017;153:1384-91.e3.

25. Cappabianca G, Paparella D, Visicchio G, Capone G, Lionetti G, Numis F, et al. Preoperative C-reactive protein predicts midterm outcome after cardiac surgery. Ann Thorac Surg 2006;82:2170-8.

26. Perrotti A, Chenevier-Gobeaux C, Ecarnot F, Bardonnet K, Barrucand B, Flicoteaux G, et al. Is endocan a diagnostic marker for pneumonia after cardiac surgery? The ENDOLUNG Study. Ann Thorac Surg 2018;105:535-41.

27. Boralessa H, de Beer FC, Manchie A, Whitwam JG, Pepys MB. C-reactive protein in patients undergoing cardiac surgery. Anaesthesia 1986;41:11-5. 